\title{
The Role of Metaphor in Advertisement Texts: A Psycholinguistic-Structural Study
}

\author{
Raafat Nazar Muneer Al-Heety ${ }^{1}$, Huda Abdulhakeem Hussein Rajab ${ }^{2}$ \\ ${ }^{1}$ Department of English, College of Education for Humanities, University of Anbar,Ramadi, Anbar, Iraq \\ ${ }^{2}$ Department of English - Al-Ma'amoon University College,Baghdad, Iraq
}

\begin{abstract}
This paper investigates the role and usage of metaphor in advertising texts from a psycho-linguistic, structural perspective. It adopts Al- Najjar (1984) structural classification of metaphor to go hand in hand with Frazier's (1987) perceptual theory of garden path of comprehension on the side of the advertisees. The analysis traces the impact of employing metaphorical texts in texting adverts. It discusses how, linguistically, unrelated words are connected together in terms of cognitive process (garden path). Indirect targeting of meaning by manipulating linguistic tools like structural options generates one of the most attractive factors for a text which is vagueness. Hovering around the exact wording of some meaning provides the advertiser enough space to insert multi-meanings, concepts, and ideas. As such, different unique impact can be made on the advertisees. The paper analyses some selected English advertising texts depending on an eclectic model made out of these two models. Finally, it ends with some conclusions which assure that relational metaphor is comprehended serially, while sentential metaphor is comprehended in a parallel garden path.
\end{abstract}

Index Terms-garden path, metaphor, relational metaphor, sentential metaphor

\section{INTRODUCTION}

Advertising, as a genre, is an art of designing economical, unique, and attractive texts that yield advertisee's acceptance and agreement. This would guarantee keeping them tuned in action and attitude (Hussein, 2009). As a written text, advertising is a means of making great impact and instant persuasion. Written texts of advertisements work in collaboration and harmony with other non-linguistic aspects or tools to achieve that impact of attractiveness. However, this paper focuses on the linguistic part of this genre. Written texts are analyzed in a structural and psycho-cognitive perspective to shed light on the characteristic traits of this genre. More specifically, it investigates the role of metaphor, as one of the linguistic deviations employed and exploited in the advertisements texts.

Textually, the analysis explains the effect of metaphor, as linguistic component, on the comprehension process by adopting the "garden path theory" as a part of the eclectic model of the research. Multi-meanings resulted due to the usage of metaphor, as a result of grammatical constraints' violations, are determined and explained structurally adopting Al- Najjar's (1984) model of metaphor. The two models adopted are strongly related in harmony where one explains the other.

To facilitate grasping the idea beyond the research, one might need to go back to the original main question; what is the reason behind texting different eye-catching and unique texts for trading something?. The answer, definitely, is to persuade the advertisee to buy the product, use the service, or agree with an idea. To achieve persuasion, advertisers should gain the advertisees' trust, logical appeal, and emotional appeal on their side. Changing or manipulating advertisees' attitudes affectively, cognitively, or behaviorally is the key principle behind advertising. Such manipulation is mainly achieved by structuring mosaic texts of advertisements to target layers of meanings. Metaphor is one of the rhetorical tools that are employed greatly in adverts to give unique pictorial forms which stimulate not only conscious communication but also unconscious effect. It contributes to the aesthetic aspect of the advertisement message and the emphasis of the key idea. Moreover, Gibbs (1994) believes that metaphor is significant to persuasion; as much of our language is metaphorically structured and can significantly change attitudes and perspectives.

\section{METAPHOR IN ADVERTISEMENTS}

Metaphor is one of the linguistic devices which is not limited to the poetic language but also used in everyday language. By using metaphor, the advert maker briefly condenses much of what sthe wants to say in one suggestive and multi-meaning slogan.

Ortony (1993, p. 307) defines metaphor as "a solar eclipse". As such, the advertiser hides the real main intent behind advertising something (to get more sales), and reveals the most

Journal of University of Human Development

Volume 5 No. 3(2019); DOI: 10.21928/juhd.v5n3y2019.pp14-17

Regular research paper: Published 4 July 2019

Corresponding author's e-mail: raafat.alheety88@ gmail.com

Copyright (C) 2019 Raafat Nazar Muneer Al-Heety, Huda Abdulhakeem Hussein Rajab. This is an open access article distributed under the

Creative Commons Attribution License (CC BY-NC-ND 4.0) 
prominent and interesting features of that promoted object to attract the advertisees' attention and interest when seen through "the right telescope". Yet, metaphorical advertisement texts are not functionally a puzzle but an asymmetry process of comprehension. Al- Nijjar (1984) argues that metaphor constitutes a thought, i. e. it maps meaning which otherwise cannot be mapped by simple language.

Psychologically, metaphor is exploited in adverts on the basis that "two stimuli may have a common effect upon a responding organism, which mediates the extension of the response" (skinner 2014, p. 97). Such extensions and expansions of meaning for a response generate infinite number of candidates for an expression and each has its own forming conceptual domains. Croft and Cruse (2004, p.221) assert that metaphor involves "the use of an expression to elicit a construal whose content is the result of an interaction between two construed domains". Hence, in the process of comprehension, the advertisees' garden path would be an elicitation of that construal. Later, Al- Najjar's (1984) structural classification of metaphor explains such a process taking into consideration the grammatical constraints and sentence's sensitivity to many pragmatic and discoursal factors that affect its plausibility.

To sum up, metaphor maps indirect source-target relation to convey concepts that are suggested or represented by others. This is often a more subconscious than conscious "associative recall" (Boyed, 2016). However, associations are tied to the social norms, values, feelings, prestige, mental modes of excitement and relaxation, and positive - or negative (behaviorl condition) (O'Shaunghnessy and O'Shaunghnessy, 2004).

\section{METHOdOLOGY AND MOdELS AdOPTED}

The approach of this paper is mainly cognitive, yet the model is an eclectic one. Since Frazier's garden path theory (1987) depends on structural constituents in its hypothesis and analysis, the researchers adopt Al- Najjar's (1984) structural model of analyzing metaphor within texts. Hence, the best example texts for analysis are adverts written texts. Advertisers use metaphor commonly, deliberately and communicatively. Different topics of advertisement texts are chosen to be analyzed tracing the structure of metaphor used within the text and the comprehension process of these texts on the advertisees' behalf adopting the garden path model.

Cognitively, Liberman and Mattingly (1985), as cited by Fodor et.al (2015, p. 423), claim that "speech production and perception are different modes of the same mechanism". Hence, the advertiser intentionally employs metaphor in adverts implying structural ambiguity which stimulates unusual garden path decoding process in the mind of the advertisee. The advertisers' target is to induce concepts that emulate other targeted ones indirectly ending in modulating or changing the advertisees' attitudes on their (the advertisers') benefit.

Structurally, Al- Najjar (1984) classifies metaphor into relational metaphor and sentential metaphor.

Relational metaphor is structured by altering the predictable selectional relations of a lexical item by unpredictable yet meaningful ones. It is very much exploited in adverts. Since the literal meaning is usually ruled out, advertisees would be able to configure the metaphorical meaning, of course with the help of the shared assumptions, experience, and cultural background.

\section{EX. Conquer the ice.}

Sentential metaphor is when an utterance carries a literal and metaphorical meaning but the latter is not mapped by altering the selectional relations. Instead, literal and metaphorical meanings are both structured to be possible and plausible. As such, layers of meaning can be exploited to be suggestive enough to persuade the advertisee.

\section{EX. He is fond of snowstorms.}

From the perspective of cognitive psychology, the advertisement text is to be parsed by the advertiser in accordance with metaphor type used in that text, sentential or relational, to be in congruity with the preferable garden path ; parallel or linear. These two models work together to match the research's main questions and aims.

In later time, Frazier and Clifton (1996, p. 4) discussed "how much human sentence-parsing mechanism responds to local or temporary structural ambiguities "that are so common in adverts. Prediction factor and structurally favored forms play a great role in the type of these ambiguities (metaphor).

To summarize, the garden path model is a serial modular parsing one. It suggests that a single parse is constructed by a syntactic module, contextual and semantic factors that influence processing at a later stage. (Wikipedia)

\section{ANALYSIS AND DISCUSSION}

The following advertisements texts employ metaphor to promote different objects and ideas in a creative and attractive way.

\section{1- See The Leaning Tower of Pizza.}

According to Al- Najjar's model, the metaphor used in this text is relational metaphor. Structurally, the sentence is grammatically correct, yet two meanings are possible. The word tower is metaphorically used to extend the associative meanings that are carried by the phrase "Leaning tower". Moreover, the phonological aspect is well exploited in the use of words (Pisa /pi:zə/, Pizza /pi:tsə/) as both have somehow the same pronunciation except for the sounds $/ \mathrm{t} / \mathrm{and} / \mathrm{s} /$ in pizza and the $/ z /$ sound in Pisa. Perceptually, it is a type of mind deceiving with an interpretation (meaning) of high popularity and frequency. Without the last word spelling difference, the advertisee would keep inferring that it is all about the famous leaning tower of Pisa. This meaning is indirectly induced in a tricky and interesting way to promote Pizza in terms of the fame of the tower of Pisa.

Psychologically, according to the garden path model, a syntactic level is first adopted in decoding the text, then a semantic level is stimulated to decide the meant garden path. Priming-targeting relationship is intentionally made indirect and loaded with various additive linguistic and extra-linguistic devices. Parsing the meaning of this advert text, being parallel or linear, would make the advertisee think of and consider the first interpretation of " the leaning tower of Pisa", due to the effect of pronunciation of the two words Pisa and Pizza. The 
word "Pizza" refutes the whole interpretation which is built up by the advertisee's mind. This makes himlher reconsider new interpretations and associative inferences, yet, not much far away from the first interpretation since the targeted meaning is induced within the use of metaphor. Metaphor is based on the comparison between two things, so there would be much of similarity as much of difference. However, such a comparison employed within metaphor is one of the devices used to satisfy the aims of advertising as a genre.

The role of metaphor here is to add meaning in a tricky, purposeful, interesting, economic and attractive way. This would provoke the advertisees to resolve ambiguity in a smooth, interesting and innovated manner which keeps a unique effect on their attitudes. As such, the goals of the advert are achieved. Also, it is important to mention that context, colors, image etc.., (non-linguistic factors) have a great role in priming the targeted meaning in the mind of the advertisee that leads to the targeted garden path.

\section{2- Cheat death.}

\section{The antioxidant power of pomegranate juice.}

This advert is skillfully formulated and prudently executed. Metaphor, as a linguistic device, dominates the idea behind the text from the very beginning with the help of non-linguistic factors. Structurally, the metaphorical phrase "Cheat death" is a relational metaphor, since the literal meaning is ruled out due to the meant words' selectivity deviation. This advert is so impressive where a type of playing on words is amazingly implemented. The verb (cheat) here is used metaphorically since death, logically, cannot be cheated. It is used in an innovated, eye-catching, provocative phrase. Since the idea of cheating death is clearly presented to target the metaphorical meaning behind it, the advertisee would search the hidden meaning as the advertiser is keenly supporting this metaphor with an assertion statement to the subject. It is intended to make sense of the connection between metaphor used and the idea of the advert.

Moreover, perceptually, the advertisee would discard the literal meaning of the metaphor used from the very beginning of parsing the phrase "cheat death". The advertisee realizes that there is something to be configured from such a comparison embedded within the use of metaphor.

The garden path of structuring the targeted meaning would be a linear one, as the advertisee is anticipating more information to come. Subject assertion "the antioxidant power of pomegranate juice" helps in defining and building up the right garden path to the targeted meaning. Inferences will accumulate with each portion of the sentence encountered. The meaning is already deceived to make an interesting, attractive, and creative connection to promote the meant product. Antioxidants are known for their positive activity for the body health. Words are selected deliberately to make such associative recalls among meaningful and attractive concepts.

Accordingly, it is noticed that the advert text would be effective as much as it is, linguistically, well-formed to modulate the advertisees' attitudes positively towards that product, service, or idea. The advert maker is completely aware that adverts texting in such economic, deviated and manipulated way is not merely for complicating interpretation; as it is not a puzzle. However, the text is obscured keenly and cautiously to arise suspense and interest of the advertisees. Also, texts would be loaded with additive and associative meanings to target multi-meanings which affect the wider scope of plausible interpretations. This would go along with different attitudes of advertisees. Psycho-linguistically, associative bonds and garden paths can be activated indirectly to reinforce the targeted ones in terms of others of high frequency and memorability.

\section{3- "It's Toasted" to taste better! \\ (WCKY strike) Cigarettes.}

According to Al-Najjar model, metaphor in this example is sentential one as the sentence is grammatically and semantically correct but within the advert context, it is of multiinterpretations. The advert maker facilitated deciphering induced meaning in such implied comparison by using nonlinguistic devices (picture of a man who is smoking a cigarette). The brand name of that type of cigar was mentioned at the end to reveal an interesting comparison. The brand name and context decide what garden path the comprehension process adopts

Perceptually, the advertisee can make sense of the statement "it's toasted" to taste better!' quite easily with an associative recall to "bread" as it is the most collective meaning attached to the word "toasted". The anticipation of something edible and testable is highly supported. Yet, the non-linguistic factors reveal something else. Here, two or more interpretations can go parallel in the mind of the advertisee as sthe is trying to find the right garden path to the meant meaning. The brand name of the cigarettes with the picture elevates one of the interpretations highlighting the meant meaning in a purposeful, indirect association-binding. However, such indirect simulation and stimulation for one concept in terms of the other's associative meanings are skillfully exploited by the advertisee for achieving the maximum acceptability, plausibility, and memorability. Although inferences vary among individuals, yet the advertiser is aware of keeping it easily and interestingly understood. Metaphor, here, is not for obscuring the text for the sake of obscurity, but for creating a corona of meanings, and an associative network to achieve attractiveness and effectiveness.

\section{4- Save the Whales \\ Lose the blubber: Go Vegetarian}

This advert has more than one possible interpretation. Multimeanings arise from the three phrases in sequences (save the whales), (lose the blubber), and (go vegetarian). Making sense of these three imperative sentences, in relation to each other, depends on the suggestivity of wording and context, as well as, the observability of non-linguistic factors (image). According to Al-Najjar model, the metaphor, which lies in the first phrase (Save the Whales), holds the targeted meaning implied within the text. It is a sentential type of metaphor; it has two possible and plausible meanings: metaphorical and literal. The two meanings arise from the fact that, according to the Urban website, this phrase is "a general expression to summarize all environmentalist aims. It is usually used mockingly, cynically, or sarcastically." In this advert, the main goal is not to mock on fat people, instead, it is used to attract their attention on the benefits of being vegetarian. By going vegetarian, weight will be lost, and whales will be saved. 
Psychologically, the advertiser, with the support of nonlinguistic factors (the image of shore and sea), would assume the common denotative meaning of the word (whale) (a huge type of fish) and use it in creating his garden path, serial or parallel, to the targeted meaning. Then, the coming two phrases change the equation. They would map another possible garden path to parse the sentence semantically and make sense of the connections among the three phrases in addition to the nonlinguistic factors (image of see and shore, with fat woman on the corner of the image). The idea of losing weight and save the fatty persons is revealed in a suggestive and manipulated way with indirect associations according to garden path theory. When the advertisee uses the syntactic information provided to make sense of the sentence, s/he would consult semantic association to reinforce one of the possible structural formulae of the text. The thematic meaning which is decided by one of the grammatical options determines the theme of the text. A tiny change in one part of the text, would lead to change meaning accordingly.

\section{CONCLUSION}

In this study, it is found that metaphor is widely used in forming adverts. It is a very effective way to attract the advertisee's attention to the targeted idea. The meanings the metaphor provides should be plausible and not distracting. It is concluded that, according to structure, mostly all relational metaphor exploited in adverts would take serial garden path in determining their meaning (comprehension process in the mind of the advertisee). While, sentential metaphor goes in parallel with the garden path because such metaphor has valid literal and metaphorical meanings. These two meanings would make the respondent keep two possible meanings parallel until disambiguating information appears. Moreover, we notice that such obscurity of meaning is an exploiting of a sense of vagueness rather than ambiguity in its different types. The advertiser is searching for candidate expressions for one targeted idea to get different reactions from his her addressees. Therefore, metaphor is employed in a way that grasping the meaning is not a matter of disambiguating the structure but it is an indirect connection among cognitive concepts and domains, from which one can induce a meaningful correlation. Furthermore, two types of metaphor are focused on under this study. Both are used for one goal: presenting a hidden meaning in an attractive way.

Using the available devices attached to the advert, the advertisees can build the correct garden bath way (decoding the advert to infer the targeted meaning).

To sum up, metaphor is exploited in a calculative manner. Innovation, uniqueness, attractiveness, and economy are the main goals for such manipulative deviations in language.

\section{REFERENCES}

Al-Najjar, M. F. (1984). Translation as a correlative of meaning cultural and linguistic transfer between Arabic and Engish. Indiana University. Bloomington.

Boyed, N. (2016). Persuasive advertising: Connotations\& associations. Retrieved in July 2/2016 from WwW.thought co. com.

Croft. W, Cruse. A. (2004). Cognitive linguistics. Cambridge university press.

Fodor. J, Frazier. L, Merrill Garrett, Panel. G, Jacques. M. (2015). Panel Discussion: Sentence perception and sentence production.

Frazier, L. (1987). Sentence Processing: A tutorial review. In Colthheart (ed), Attention and performance 12: The psychology of reading (P.P 559-586). Hillsdale, NJ, US: Lawrence Erlbaum Associates, Inc.

Frazier. L, Jr, Charles. C. (1996). Construal. Cambridge: Massachusetts, London: England.

Gibbs, R.W.( 1994). The poetics of the mind: Figurative thought, language, and understanding. Cambridge: University press.

Hussein, R.M. (2009). ). Perceiving English language in internet \& DSR advertising: A Case of conversational implicature. Journal of Humanities. University of Anbar. (Vol. 3, No. 1 March, 2009).

Ortony, A (ed). (1993). Metaphor and thought. Cambridge. Press Syndicate of the University of Cambridge. The Pitt Building, Trumpington street. 2ed edition.

O'Shaughnessy, John \& O'Shaughnessy, Nicholas J (2004). Persuasion in advertising. Routledge, New York

Skinner, B.F.(2014). Verbal Behavior. Cambridge. Massachusetts.

https:Ilwww.Wikipedia.com.gardenpaththeory.

https: Ilwww.urbandictionary.comldefine.php?term=save20\%the $20 \%$ whales 